\title{
RANCANG BANGUN PAKAN DAN FILTERISASI PADA BUDIDAYA IKAN CHANNA MENGGUNAKAN METODE FUZZY BERBASIS ARDUINO
}

\author{
Aulya Rangga Saputra, Agung Panji Sasmito, Deddy Rudhistiar \\ Program Studi Teknik Informatika S1, Fakultas Teknologi Industri \\ Institut Teknologi Nasional Malang, Jalan Raya Karanglo km 2 Malang, Indonesia \\ ranggasaputra1718112@gmail.com
}

\begin{abstract}
ABSTRAK
Ikan hias channa atau banyak kita kenal dengan ikan gabus merupakan salah satu ikan hias air tawar yang sedang banyak digemari oleh masyarakat karena memiliki nilai jual yang tinggi, oleh karena itu dalam pembudidayaan ikan channa ini memerlukan perawatan yang tepat agar mendapatkan ikan dengan kualitas yang bagus. salah satu caranya adalah dengan melakukan pemfilteran air dan pemberian pakan yang teratur. Oleh karena itu dibutuhkan alat otomatis dengan monitoring. Alat ini memiliki beberapa komponen seperti, sensor suhu air, sensor kekeruhan dan sensor ultrasonic dengan output pompa untuk pemfilteran dan servo untuk pakan, jadi apabila kekeruhan dan suhu air tidak sesuai maka otomatis pompa akan menyala sampai batas yang ditentukan dan sistem ini juga dapat dimonitoring menggunakan web, tidak hanya itu agar penyalaan filter dapat terjaga dengan baik makan akan digunakan metode Fuzzy untuk perhitungan nilai sensornya. Jadi Fuzzy berperan penting dalam pengambilan keputusan untuk pengaktifan akuator, agar pengaktifan akuator tidak berlebihan. Fuzzy merupakan sebuah logika dimana untuk menggambil sebuah keputusan dengan keakuratan yang tinggi, salah satunya adalah fuzzy sugeno dengan aturan yang telah direpresentasi menjadi IF-THEN. Hasil yang didapatkan dari pengujian fungsional adalah berupa, nilai rata-rata error dalam sensor adalah sebesar $0.45 \%$, sedangkan untuk pengujian alat dengan kesalahan $0 \%$, dan tingkat akurasi yang tinggi dalam penggunaan fuzzy sugeno dalam perhitungan nilai sensor.
\end{abstract}

Kata Kunci: Sistem Monitoring, Logika Fuzzy, nodemcu, ikan channa, turbidity

\section{PENDAHULUAN}

Ikan hias air tawar adalah jenis ikan yang habitatnya di air tawar. Pemeliharaan ikan air tawar biasanya di akuarium atau kolam kecil yang tergantung pada pemeliharaan, jika hanya untuk kesenangan dan keindahan biasanya mereka memeliharanya pada akuarium, sedangkan jika untuk pengembangbiakan biasanya menggunakan kolam bahkan bisa dengan menggunakan akuarium kecil. Saat ini dimasa pandemi seperti sekarang ini ikan hias air tawar makin digemari oleh masayarakat sehingga animo budidaya ikan ini makin berkembang. Salah satu contonya adalah ikan gabus (channa), Ikan gabus merupakan salah satu jenis ikan karnivora air tawar yang menghuni kawasan Asia Tenggara. Di Indonesia sendiri ikan ini memiliki banyak jenis, dan Ikan ini banyak dikonsumsi oleh masyarakat jika sudah memiliki ukuran yang pas, Sedangkan untuk ikan yang berukuran kecil dan memiliki jenis tersendiri yang banyak dimanfaatkan untuk ikan hias.[1]

Terdapat banyak cara untuk membudidayakan ikan hias Channa. Prooses budidaya memerlukan perawatan agar ikan tidak mudah mati, caranya dengan melakukan pemfilteran ketika air sudah keruh dan selalu memberi pakan dengan teratur. Namun, proses budidaya ikan hias yang terjadi dimasyarakat mayoritas adalah metode konvensional dengan penggantian air dan pemberian makan secara manual oleh pemilik budidaya, Akibatnya, kualitas ikan hias channa akan tergantung pada saat pemberian pakan dan penggantian air oleh pembudidaya, dan akibatnya daya beli dari ikan tersebut menjadi rendah.

Komputer saat ini telah menjadi alat untuk menyelesaikan semua permasalahan manusia. Tidak hanya ditempat kerja, komputer juga dapat membuat program atau bermain game, bahkan digunakan sebagai alat untuk memprogram mikrokontroler [2].

Pada masa sekarang ini bidang elektonika memiliki kemajuan pesat pada bidang komputerisasi dan IoT, terutama pada IoT (Internet of Things) adalah sebuah teknologi yang memungkinkan kita untuk menghubungkan mesin, dengan sensor jaringan untuk mengelola kinerja sebuah alat agar mendapatkan sebuah data yang akurat [3].

Pada sistem ini akan menggunakan metode Logika Fuzzy. Dimana metode ini memiliki hasil keakuratan yang tinggi dalam pegambilan suatu keputusan. Dengan adanya sistem ini, perawatan ikan hias dapat dilakukan secara otomatis secara presisi agar perkembangan ikan dapat dikontrol dengan baik.

Berdasarkan paparan tersebut diketahui bahawa sejauh ini pemberian makan dan pengecekan kekeruhan air masih manual oleh pembudidaya ikan channa, dan belum banyak yang menggunakan sistem IoT (Internet of Things) untuk perkembangbiakan. Oleh karena itu melalui penelitian ini penulis menggagas perkembangan budidaya ikan channa menggunakan sistem IoT(Internet of Things) dengan metode fuzzy. Diharapkan dengan adanya alat ini para 
pembudidaya akan dimudahkan saat pembudidayaan ikan.

\section{TINJAUAN PUSTAKA}

\subsection{Penelitian Terdahulu}

Penelitian Islamy (2015) dengan judul "Sistem Monitoring Kualitas Air Budidaya Gurami Berbasis Arduino Menggunakan Metode Weighted Product". Menghasilkan sebuah penelitian yaitu sebuah monitoring kualitas air kolam Gurame dengan menggunakan sistem pengambilan keputusan metode Weighted Product. Hasil penelitian menunjukan bahwa dalam proses monitoring kadar air atau $\mathrm{Ph}$ yang sagat dibutuhkan dalam pembudidayaan ikan gurami, menggunakan sensor ph, suhu dan sensor turbidity untuk mendeteksi air.[4]

Kemudian Qalit dkk (2019) dengan judul "Rancang Bangun Prototipe Pemantauan Kadar pH dan Kontrol Suhu Serta Pemberian Pakan Otomatis pada Budidaya Ikan Lele Sangkuriang Berbasis IoT". Menghasilkan prototipe pemberian pakan berdasarkan golongan umur ikan lele dan kontrol kondisi air secara otomatis . [5].

Kemudian Dewantoro (2016) dengan judul "Pembangunan Sistem Pantau Smart Fish Farm Menggunakan Arduino Berbasis Internet Of Things (Iot) Terhadap Budidaya Ikan". Menghasilkan sebuah sistem pemantau kondisi kolam ikan pada UD. Menggunakan internet dan android sebagai media untuk mengintegrasikan dengan perangkat lainnya. [2]

Prabowo dkk (2020) dengan judul "Sistem Monitoring Dan Pemberian Pakan Otomatis Pada Budidaya Ikan Menggunakan Wemos Dengan Konsep Internet Of Things (IoT)". Dengan hasil perangkat elektronik sistem monitoring dan pemberian pakan otomatis untuk budidaya ikan yang disampaikan kepada peternak yang memberikan informasi tentang pemberian pakan. Sistem pakan harus mudah diakses. [6]

Hudin dkk (2018) dengan judul "Implementasi Model Agile Pada Monitoring Suhu Kolam Ikan Dengan Algoritma Fuzzy Logic Berbasis Internet Of Thing (IoT)". Menghasilkan suatu sistem monitoring suhu kolam ikan dengan menggunakan media NodeMCU. [7]

\subsection{Pengertian Fuzzy}

Logika Fuzzy adalah sebuah peningkatan dari Bolean. Logika Fuzzy menggantikan kebenaran boolean dengan tingkat kebenaran. Oleh karena itu Fuzzy dapat memungkingkan nilai keanggotaan antara 0 dan 1, dan dalam bentuk lingusitik konsep tidak pasti seperti "sedikit", "setengah" dan "banyak". Fuzzy metode Sugeno merupakan metode inferensi fuzzy untuk aturan yang direpresentasikan dalam bentuk IF - THEN, dimana output sistem tidak berupa himpunan fuzzy, melainkan berupa konstanta atau persamaan linear.[8] Kali ini saya akan menggunakan Fuzzy sebagai metode untuk mempermudah penjumlahan nilai sensor agar akuator dapat berfungsi dengan baik, hasil perhitungan fuzzy akan dimasukkan kedalam penggunaan penggunaan pompa sebagai pergantian air, penggunaan servo untuk seberapa banyak pakan yang akan dikeluarkan dengan patokan (sedikit, sedang, dan banyak)

\subsection{Ikan channa}

Ikan Channa merupakan sebuah spesies ikan gabus yang banyak tinggal di sungai-sungai di Indonesia. Ikan ini termasuk kedalam ikan karnivora, di Indonesia sendiri ikan ini memiliki banyak jenis, dan warna yang berbeda, untuk ikan yang memiliki jenis tersendiri ikan ini banyak digunakan untuk ikan hias karena memiliki karakterisitik dan warna yang bagus [1].

Ikan channa banyak hidup dan berkembang dirawa-rawa dan sungai dengan kandungan $\mathrm{pH}$ yang rendah dan air berwarna kecoklatan dengan suhu air berkisar antara 25-29 C, oleh karena jika suhu, kekeruhan dan $\mathrm{pH}$ air tidak sesuai makan akan membuat ikan mengalami gejala setres[14].

Ikan channa memiliki pola pertumbuhan yang allometrik yaitu pertumbuhan berat dari ikan lebih cepat dibanding pertambahan panjang ikan, oleh karena itu berkaitan dengan sifat agresifitas dalam pencarian pakan[15]

\subsection{Arduino UNO R3}

Arduino Uno R3 adalah sebuah board berbasis mikrokontroler pada ATmega328, yang digunakan sebagai otak atau pusat kontrol untuk semua sensor board ini memiliki pin analog, digital, koneksi USB, ICSP header, dan tombol reset, Hanya dengan menyambungkan dengan kabel USB, bahkan dapat menggunakan baterai untuk menghidupkan mikrokontroler ini. [9] Gambar Arduino UNO R3 ditunjukan pada Gambar 1

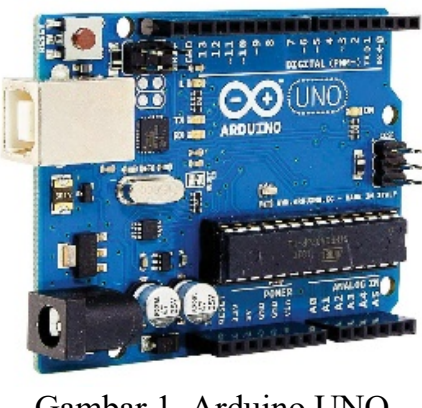

Gambar 1. Arduino UNO

\subsection{Turbidity}

Turbidity adalah sebuah sensor yang dapat mendeteksi kekeruhan air dengan cara pemantulan cahaya yang memiliki semakin tinggi partikel diair berarti air tersebut semakin keruh, dari situ dapat dapat disimpulkan jika kekeruhan air semakin keruh makan tegangan dalam sensor akan berubah.[10] Gambar sensor turbidity ditunjukan pada Gambar 2 


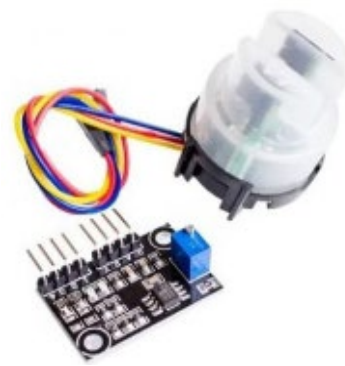

Gambar 2. Turbidity

\subsection{Sensor Suhu DS18B20}

Sensor suhu DS18B20 adalah sensor suhu yang memiliki keluaran digital. DS18B20 dengan tingkat akurasi tinggi, $0,5^{\circ} \mathrm{C}$ pada rentang suhu $-10^{\circ} \mathrm{C}$ sampai $+85^{\circ} \mathrm{C}$, tidak hanya itu, sensor ini juga memiliki casing atau wadah yang tahan air[11] Gambar sensor air dapat dilihat di Gambar 3.

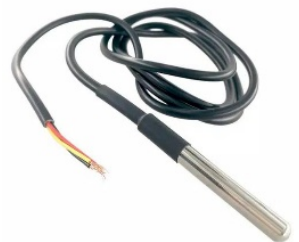

Gambar 3. Sensor suhu DS18B20

\subsection{Sensor Ultrasonic}

Sensor Ultrasonik HCSRF-04, memiliki prinsip kerja, yaitu transmitter memancarkan seberkas sinyal ultrasonik $(20 \mathrm{KHz})$ yang berbentuk pulsa, kemudian jika didepan HCSFR-04 ada objek padat maka receiver akan menerima pantulan sinyal ultrasonik tersebut Receiver akan membaca lebar pulsa (dalam bentuk PWM) yang dipantulkan objek dan selisih waktuk pemancaran.[9] Gambar sensor dapat dilihat di Gambar 4

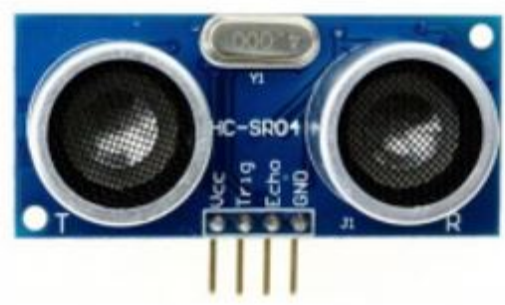

Gambar 4. Sensor Ultrasonic

\section{METODE PENELITIAN}

Metode yang digunakan pada penelitian ini adalah Research and Development dengan tujuan mengembangkan alat otomatisasi sistem pakan dan suhu air dalam pemudidayaan ikan channa. Aplikasi ini dikembangkan berdasarkan hasil analisis masalah yaitu masih banyak pembudidaya menggunakan sistem konvensional saat pembudidayaan ikan channa yang tidak efektif.

\subsection{Fungsi Keanggotaan Fuzzy}

Fungsi keanggotaan adalah suatu kurva yang menunjukkan pemetaan titik input kedalam nilai kenaggotaan yang memiliki nilai interval 1 an tara 0 .

a. Fungsi Grafik Kekeruhan

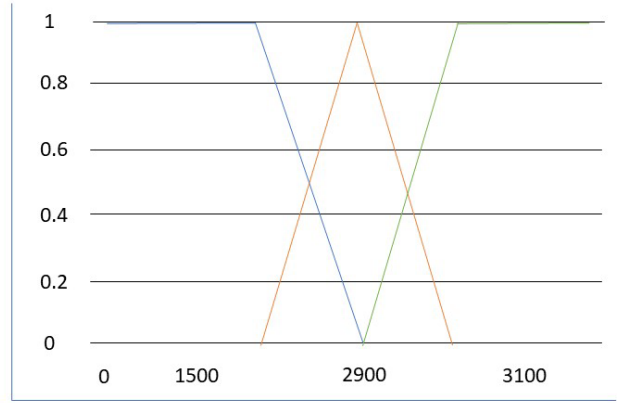

Gambar 5. Fungsi Grafik Kekeruhan

Fungsi keanggotaan dirumuskan seperti berikut.

$\operatorname{JERNIH}[x]=\left\{\begin{array}{c}1 \\ \frac{2900-x}{2900-2750} \\ 0\end{array}\right.$

$$
\begin{aligned}
, x \leq & 2750 \\
& 2750<x<2900 \\
, \geq & 2900
\end{aligned}
$$

$\operatorname{JERNIH}[x]=\left\{\begin{array}{c}1 \\ \frac{2900-x}{2900-2750} \\ 0\end{array}\right.$

,$x \leq 2750$

$2750<x<2900$

,$\geq 2900$

$\operatorname{JERNIH}[x]=\left\{\begin{array}{c}1 \\ \frac{2900-x}{2900-2750} \\ 0\end{array}\right.$

,$x \leq 2750$

$2750<x<2900$

, $\geq 2900$

b. Fungsi Grafik Suhu

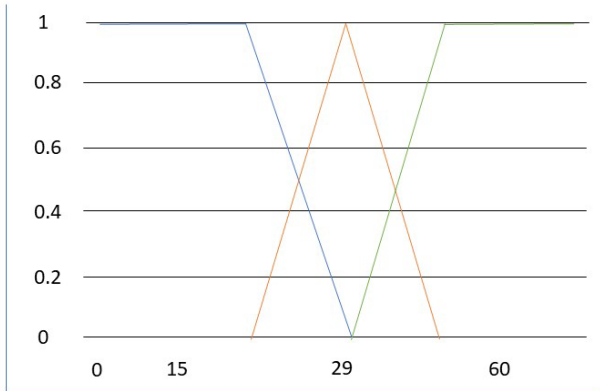

Gambar 6. Fungsi Grafik Suhu

Fungsi keanggotaan dirumuskan seperti berikut.

$\operatorname{DINGIN}[x]= \begin{cases}1 & , x \leq 25 \\ \frac{25-x}{25-29} & , 25<x<29 \\ 0 & , x \geq 29\end{cases}$ 


$$
\begin{aligned}
& \text { NORMAL }[x]=\left\{\begin{array}{cc}
\frac{x-25}{29-25} & , x \leq 25 \\
1 & , 25<x<29 \\
\frac{34-x}{34-29} & , x=29
\end{array}\right. \\
& \text { PANAS }[x]= \begin{cases}0 & , 29<x<34 \\
\frac{x-29}{50-29} & , x \leq 29 \\
1 & , 29<x<50\end{cases} \\
&
\end{aligned}
$$

c. Rule

[R1] IF Kekeruhan Jernih, AND Suhu Dingin, THEN Pump 1 off, AND Servo Banyak.

[R2] IF Kekeruhan Jernih, AND Suhu Sedang THEN Pump off, AND Servo Banyak.

[R3] IF Kekeruhan Jernih, AND Suhu Panas, THEN pump off, AND Servo Banyak.

[R4] IF Kekeruhan Agak Keruh, AND Suhu Dingin, THEN Pump off, AND Servo Sedang.

[R5] IF Kekeruha Agak Keruh AND Suhu Sedang THEN Pump on, AND Servo Sedang.

[R6] IF Kekeruhan Agak Keruh AND Suhu Panas, THEN Pump on, AND Servo Sedang.

[R7] IF Kekeruhan Keruh, AND Suhu Dingin, THEN Pump on, AND Servo Sedikit.

[R8] IF Kekeruhan Keruh AND Suhu Sedang THEN Pump on, AND Servo Sedikit.

[R9] IF Kekeruhan Keruh, AND Suhu Panas, THEN Pump on, AND Servo Sedikit.

Perhitungan untuk suhu :

$$
\begin{aligned}
& \mu \text { dingin }(25)=\frac{30-25}{30-45}=\frac{5}{10}=0,5 \\
& \mu \text { sedang }(25)=\frac{25-20}{30-20}=\frac{5}{10}=0,5 \\
& \mu \text { panas }(25)=0 \\
& \mu \text { dingin }(27)=\frac{32-27}{32-42}=\frac{5}{10}=0,5 \\
& \mu \text { sedang }(27)=\frac{27-22}{42-22}=\frac{5}{10}=0,5 \\
& \mu \text { panas }(27)=0 \\
& \mu \text { dingin }(30)=0 \\
& \mu \text { sedang }(30)=\frac{35-30}{35-25}=\frac{5}{10}=0,5 \\
& \mu \text { panas }(30)=\frac{30-25}{35-25}=\frac{5}{10}=0,5
\end{aligned}
$$

Perhitungan untuk Kekeruhan :

$$
\begin{aligned}
& \mu \text { Jernih (2750) : } 1 \\
& \mu \text { Agak Keruh (2750) : } 0 \\
& \mu \text { Keruh (2750) }: 0 \\
& \mu \text { Jernih (2900) : } 0 \\
& \mu \text { Agak Keruh (2900) : } 1 \\
& \mu \text { Keruh (2900) : } 0 \\
& \mu \text { Jernih (2920) : } 0 \\
& \mu \text { Agak Keruh (2920) : } 0 \\
& \mu \text { Keruh (2920) : } 1
\end{aligned}
$$

\subsection{Alur Flowchart System}

Adapun alur Flowchart Sistem dijelaskan pada Gambar 7.

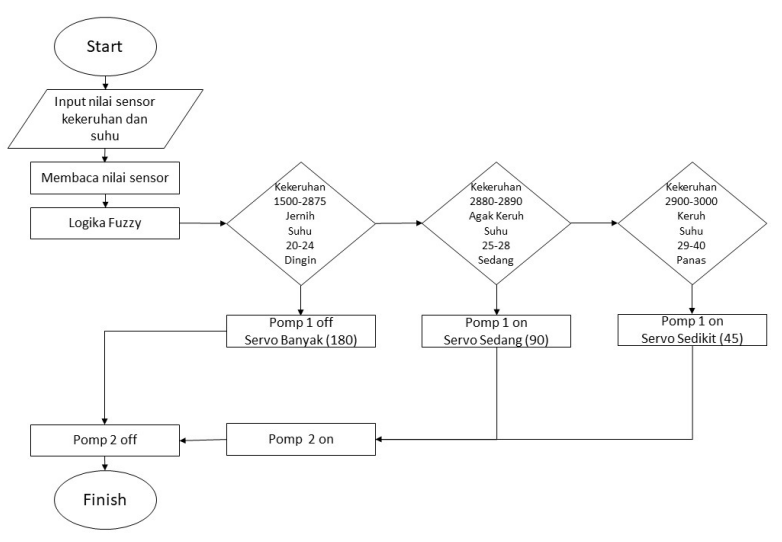

Gambar 7 Flowchart Sistem

Berdasarkan flowchart pada gambar 7 alur dari flowchart adalah, merupakan alur proses dari sistem, Pertama sensor akan menginputkan variable dari sensor kekeruhan, sensor suhu air kemudian dikirmkan ke perangkat mikrokontroler untuk diproses kedalam mengambil keputusan atau fuzzyfikasi dengan batasan - batasan nilai sensor seperti yang ada diatas, yaitu jika kekeruhan dan suhu melebihi batas maka pompa 1 akan menyala, kemudian sensor ultrasonic akan bekerja memonitoring banyaknya air yang terbuang, jika air sudah memenuhi batas yang telah ditentukan, makan pompa 2 akan menyala sampai batas yang ditentukan yang dimonitoring oleh ultrasonic agar air tidak melebihi dari kapsitas. Untuk penggunaan pakan servo otomatis akan bergerak sesuai yang telah dijadwalkan, servo juga memasuki fuzzy, jika sensor mendeteksi kekeruhan air maka otomatis servo akan membuka sesuai kekeruhan air, jika air jernih maka servo akan membuka 180 derajat, maka pakan yang jatuh akan banyak.

\subsection{Diagram Blok Sistem}

Adapun alur proses Sistem dijelaskan pada Gambar 8.

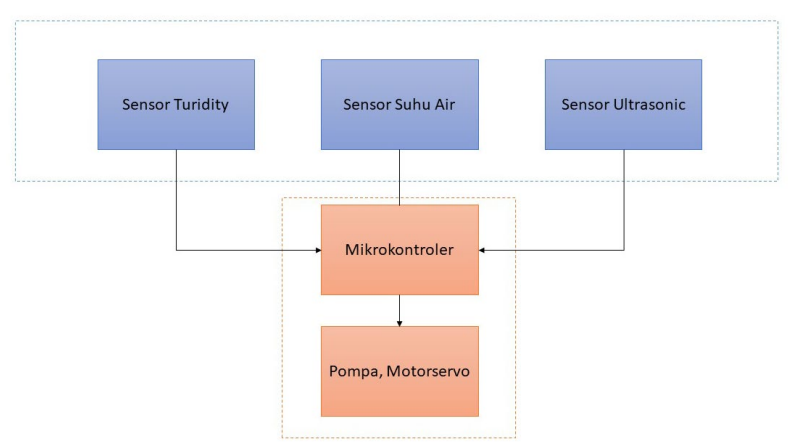

Gambar 8 Diagram Blok 
Berdasarkan blok diagram pada Gambar 8 menunjukkan bahwa data masukan berupa Data trudity, data suhu air, dan data turbidity mengirim data ke mikrokontroler, setelah pengiriman data dari sensor akan diteruskan ke pompa dan servo.

\subsection{Perancangan Prototype Desain}

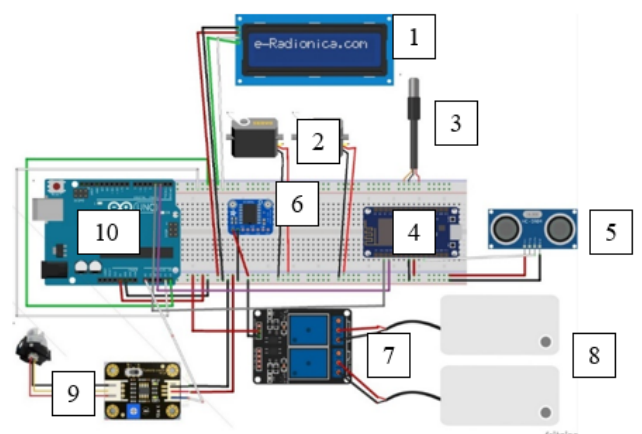

Tabel 1 Wiring

\begin{tabular}{|l|l|}
\hline No & Nama \\
\hline 1 & LCD \\
\hline 2 & Servo \\
\hline 3 & Sensor Suhu Air \\
\hline 4 & NodeMCU \\
\hline 5 & Ultrasonic \\
\hline 6 & RTC \\
\hline 7 & Relay \\
\hline 8 & Pompa \\
\hline 9 & Sensor Kekeruhan \\
\hline 10 & Arduino UNO \\
\hline
\end{tabular}

\section{IMPLEMENTASI DAN PENGUJIAN}

\subsection{Rancangan Prototype}

Rancangan Prototype alat merupakan cikal bakal dari alat otomatisasi.

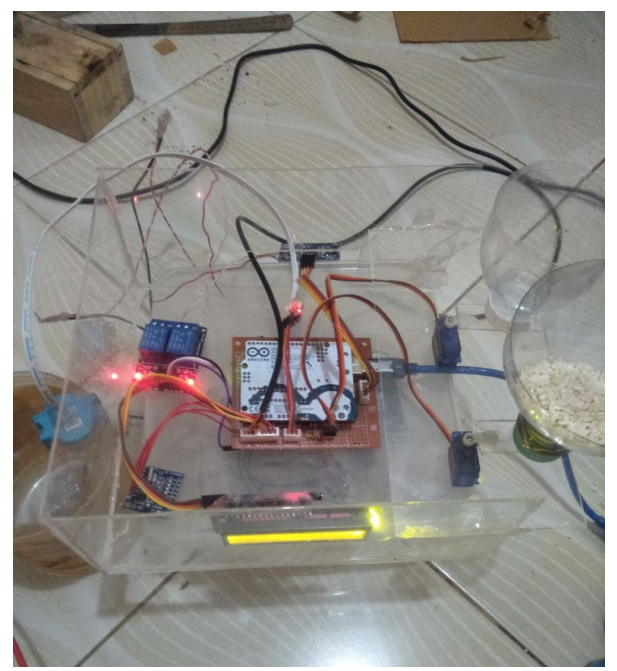

Gambar 9. Rancangan Prototype Alat

Pada gambar 9, merupakan sebuah rancnagan prototype sistem otomatisasi dalam pembudidayaan ikan chana yang dibuat oleh penulis. Dapat dilihat pada gambar terdapat dua servo untuk pembeda pemberian pakan dan dua pompa untuk filterisasi air.

\subsection{Hasil Prototype}

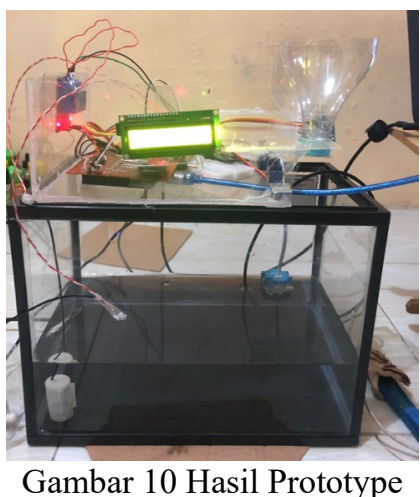

Pada Gambar. 10 merupakan hasil dari prototype alat yang telah dikaembangkan dari rancangan prototype.

\subsection{Pengujian Sensor Suhu}

Tabel 2. Hasil pengujian sensor suhu

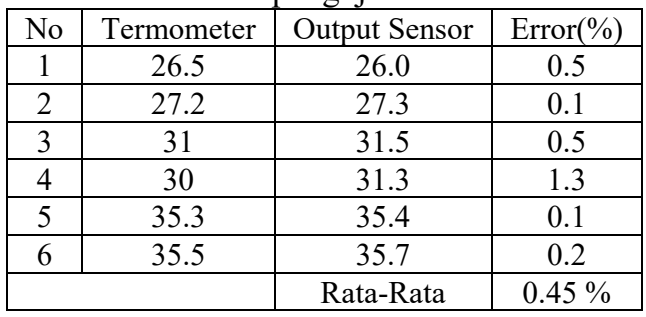

Pada Tabel 1 merupakan hasil dari pengujian sensitivitas sensor yang dibandingkan dengan termometer gelas, dengan didapatkan nilai rata-rata error sebesar $0,45 \%$.

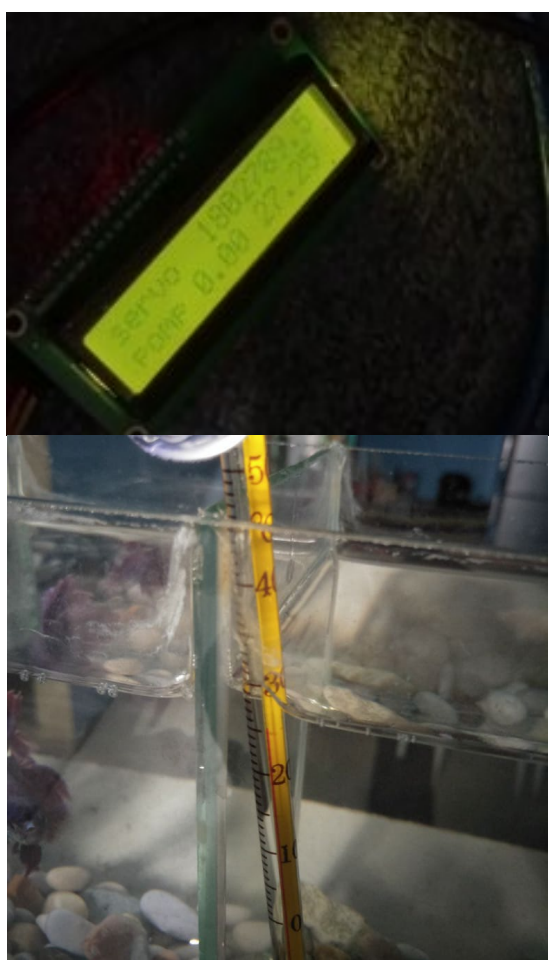

Gambar 10. Pengujian sensor suhu 


\subsection{Pengujian Alat dan Komponen}

Pengujian alat dan komponen dilakukan dengan cara menguji semua sensor dan output seperti pada gambar 11 berikut

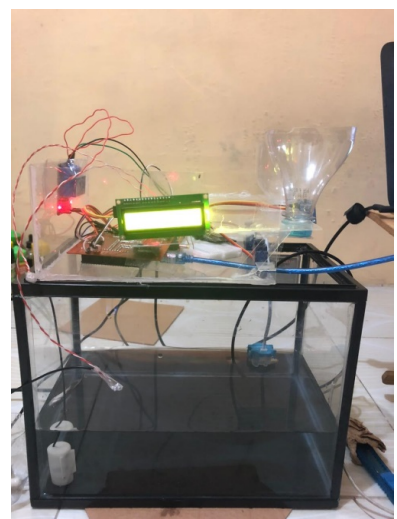

Gambar 10. Pengujian alat dan komponen

Tabel 3 Pengujian alat

\begin{tabular}{|c|c|c|c|c|}
\hline No & Kekeruhan & Suhu & Pompa & Kesimpulan \\
\hline 1 & 1500 & 24 & off & Sesuai \\
\hline 2 & 2760 & 23 & off & Sesuai \\
\hline 3 & 2790 & 22 & off & Sesuai \\
\hline 4 & 2800 & 29 & off & Sesuai \\
\hline 5 & 3000 & 35 & on & Sesuai \\
\hline 6 & 2900 & 23 & on & Sesuai \\
\hline 7 & 1665 & 25 & off & Sesuai \\
\hline
\end{tabular}

\subsection{Perhitungan fuzzy}

Pengujian perhitungan metode Fuzzy dan pengambilan data secara manual, pengujian alat di hari 1 dan 2. Perhitungan dilakukan secara manual sesuai dengan perhitungan Fuzzy secara manual. Langkah-langkahnya sebagai berikut.

1. Perhitungan Manual Kekeruhan:

Jernih (2750) : 1

Agak Keruh (2750): 0

Keruh (2750) : 0

2. Perhitungan Manual Suhu:

Dingin (27) $: 0,5$

Sedang (27) $: 0,5$

Panas (27) :0

3. Mencari Nilai $Z$

[R1] : MIN $\mu$ Kekeruhan (2750); MIN $\mu$ Suhu (27)

$\operatorname{MIN}(1 ; 0,5)$

Nilai $Z=1$

$\mathrm{Z}=1$

[R2] : MIN $\mu$ Kekeruhan (2750) ; MIN $\mu$ Suhu (27)

$\operatorname{MIN}(1 ; 0,5)$

Nilai $Z=1$

$\mathrm{Z}=1$

[R3] : MIN $\mu$ Kekeruhan (2750) ; MIN $\mu$ Suhu (27)

$\operatorname{MIN}(1 ; 0)$

Nilai $Z=1$

$\mathrm{Z}=1$

[R4] : MIN $\mu$ Kekeruhan (2750); MIN $\mu$ Suhu (27)

$\operatorname{MIN}(0 ; 0,5)$

Nilai $Z=0$

$\mathrm{Z}=0$

[R5] : MIN $\mu$ Kekeruhan (2750); MIN $\mu$ Suhu (27)
$\operatorname{MIN}(0 ; 0,5)$

Nilai $Z=0$

$\mathrm{Z}=0$

[R6] : MIN $\mu$ Kekeruhan (2750); MIN $\mu$ Suhu (27)

$\operatorname{MIN}(0 ; 0)$

Nilai $Z=0$

$\mathrm{Z}=0$

[R7] : MIN $\mu$ Kekeruhan (2750); MIN $\mu$ Suhu (27)

$\operatorname{MIN}(0 ; 1)$

Nilai $Z=1$

$\mathrm{Z}=1$

[R8] : MIN $\mu$ Kekeruhan (2750); MIN $\mu$ Suhu (27)

$\operatorname{MIN}(0 ; 0,5)$

Nilai $Z=0$

$\mathrm{Z}=0$

[R9] : MIN $\mu$ Kekeruhan (2750) ; MIN $\mu$ Suhu (27)

$\operatorname{MIN}(0 ; 0)$

Nilai $Z=0$

$Z=0$

$\mathrm{Z}$ Total $=((\mathrm{a} 1 * \mathrm{z} 1)+(\mathrm{a} 2 * \mathrm{z} 2)+(\mathrm{a} 3 * \mathrm{z} 3)+$

$(a 4 * z 4)+(a 5 * z 5)+(a 6 * z 6)+(a 7 * z 7)+$

$(\mathrm{a} 8 * \mathrm{z} 8)+(\mathrm{a} 9 * \mathrm{z} 9)) /(\mathrm{a} 1+\mathrm{a} 2+\mathrm{a} 3+\mathrm{a} 4+\mathrm{a} 5+$ $\mathrm{a} 6+\mathrm{a} 7+\mathrm{a} 8+\mathrm{a} 9)=1$

Kondisi kekeruhan (2750) dan kondisi suhu (27) mendapatkan output pompa 1 (Open).

\subsection{Pengujian User}

Pada pengujian user ini dilakukan pengetesan langsung ketempat pembudidayaan ikan. Dengan memberikan pertanyaan ke-user bagaimana tentang alat yang telah diuji kedalam budidayanya.

Tabel 4 Hasil Pengujian Alat pada Uer

\begin{tabular}{|l|l|l|l|l|}
\hline No & Kekeruhan & Suhu & Pompa I & Servo \\
\hline 1 & 2680 & 25 & off & 180 \\
\hline 2 & 2760 & 23 & off & 180 \\
\hline 3 & 2850 & 25 & off & 180 \\
\hline 4 & 2800 & 25 & off & 180 \\
\hline 5 & 2898 & 30 & on & 90 \\
\hline 6 & 2990 & 29 & on & 45 \\
\hline 7 & 1665 & 25 & off & 180 \\
\hline
\end{tabular}

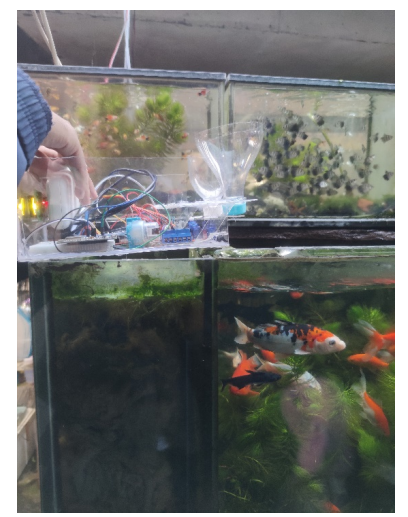

Gambar.11 Pengujian User 
Tabel 5 Hasil pengujian user

\begin{tabular}{|c|c|c|c|c|}
\hline No & Pertanyaan & $\begin{array}{l}\text { Sangat } \\
\text { Setuju }\end{array}$ & Setuju & $\begin{array}{l}\text { Tidak } \\
\text { Setuju }\end{array}$ \\
\hline 1 & $\begin{array}{l}\text { Apakah alat mudah } \\
\text { digunakan? }\end{array}$ & & & $\checkmark$ \\
\hline 2 & $\begin{array}{l}\text { Apakah monitoring berjalan } \\
\text { dengan baik? }\end{array}$ & $\checkmark$ & & \\
\hline 3 & $\begin{array}{l}\text { Apakah membatu } \\
\text { meringankan pekerjaan dari } \\
\text { user? }\end{array}$ & $\checkmark$ & & \\
\hline 4 & $\begin{array}{l}\text { Apakah hasil dari data ini } \\
\text { akurat? }\end{array}$ & & $\checkmark$ & \\
\hline 5 & $\begin{array}{l}\text { Apakah hasil dari sistem ini } \\
\text { sesuai dengan apa yang telah } \\
\text { direncanakan?? }\end{array}$ & & $\checkmark$ & \\
\hline
\end{tabular}

\subsection{Pengujian Blackbox}

Pada pengujian sistem ini merupakan proses menampilkan semua sistem web berjalan dengan baik.

Tabel 6 Pengujian blackbox

\begin{tabular}{|c|l|c|c|c|}
\hline No. & Pengujian & Nama Event & $\begin{array}{c}\text { Hasil } \\
\text { Yang } \\
\text { Diharapkan }\end{array}$ & Hasil \\
\hline 1. & $\begin{array}{l}\text { Menu } \\
\text { Kekeruhan }\end{array}$ & $\begin{array}{c}\text { Klik button } \\
\text { Kekeruhan }\end{array}$ & $\begin{array}{c}\text { Tampil info } \\
\text { kekeruhan }\end{array}$ & Berhasil \\
\hline 2. & $\begin{array}{l}\text { Menu } \\
\text { Suhu }\end{array}$ & $\begin{array}{c}\text { Klik Button } \\
\text { Suhu }\end{array}$ & $\begin{array}{c}\text { Tampil info } \\
\text { suhu }\end{array}$ & Berhasil \\
\hline 3. & $\begin{array}{l}\text { Jadwal } \\
\text { Pakan }\end{array}$ & $\begin{array}{c}\text { Klik Buton } \\
\text { Jadwal } \\
\text { Pakan }\end{array}$ & $\begin{array}{c}\text { Tampil info } \\
\text { jadwal pakan } \\
\text { ikan }\end{array}$ & Berhasil \\
\hline 4. & Realtime & Realtime & $\begin{array}{c}\text { Tampil info } \\
\text { realtime nilai } \\
\text { sensor }\end{array}$ & Berhasil \\
\hline
\end{tabular}

\section{KESIMPULAN DAN SARAN}

\subsection{Kesimpulan}

Berdasarkan beberapa pengujian yang telah dilakukan didapatkan kesimpulan :

1. Hasil dari pengujian alat dapat berjalan dengan baik, dan berfungsi seperti yang telah direncanakan.

2. Pengujian untuk web berjalan dengan baik, dapat mengirimkan nilai sensor dengan realtime.

3. Pengujian alat berjalan dengan presentase kesalahan $0 \%$.

\subsection{Saran}

Berdasarkan penelitian yang telah dilakukan, maka penulis dapat memberikan saran-saran untuk pengembangan selanjutnya antar lain :

1. Mengembangkan sistem monitoring pada pemrograman android.

2. Menambahkan notifikasi berupa pemberitahuan pada pemrograman android apabila suhu kurang atau melebihi suhu normal.

\section{DAFTAR PUSTAKA}

[1] Listyanto, N., \& Andriyanto, S. (2009). Ikan gabus (Channa striata) manfaat pengembangan dan alternatif teknik budidayanya. Media Akuakultur, 4(1), 18-25.
[2] Dewantoro, W. (2016). Pembangunan Sistem Pantau Smart Fish Farm Menggunakan Arduino Berbasis Internet Of Things (IOT) Terhadap Budidaya Ikan (Doctoral dissertation, Universitas Komputer Indonesia).

[3] Kadir, S. F. (2019). Mobile Iot (Internet Of Things) Untuk Pemantauan Kualitas Air Habitat Ikan Hias Pada Akuarium Menggunakan Metode Logika Fuzzy. Jati (Jurnal Mahasiswa Teknik Informatika), 3(1), 298-305.

[4] Islamy, W. H. (2019). SISTEM MONITORING KUALITAS AIR BUDIDAYA GURAMI BERBASIS ARDUINO MENGGUNAKAN METODE WEIGHTED PRODUCT. JATI (Jurnal Mahasiswa Teknik Informatika), 3(1), 314-319.

[5] Qalit, A., Fardian, F., \& Rahman, A. (2017). Rancang Bangun Prototipe Pemantauan Kadar pH dan Kontrol Suhu Serta Pemberian Pakan Otomatis pada Budidaya Ikan Lele Sangkuriang Berbasis IoT. Jurnal Karya Ilmiah Teknik Elektro, 2(3).

[6] Prabowo, R. R., Kusnadi, K., \& Subagio, R. T. (2020). SISTEM MONITORING DAN PEMBERIAN PAKAN OTOMATIS PADA BUDIDAYA IKAN MENGGUNAKAN WEMOS DENGAN KONSEP INTERNET OF THINGS (IoT). Jurnal Digit, 10(2), 185-195.

[7] Hudin, J. M., Susilwati, D., \& Faizal, M. A. (2018). Implementasi Model Agile Pada Monitoring Suhu Kolam Ikan Dengan Algoritma Fuzzy Logic Berbasis Internet Of Thing (IOT). Jurnal Swabumi, 6(1), 128-138.

[8] Kadir, S. F. (2019). Mobile Iot (Internet Of Things) Untuk Pemantauan Kualitas Air Habitat Ikan Hias Pada Akuarium Menggunakan Metode Logika Fuzzy. Jati (Jurnal Mahasiswa Teknik Informatika), 3(1), 298-305.

[9] Samsugi, S., Mardiyansyah, Z., \& Nurkholis, A. (2020). Sistem Pengontrol Irigasi Otomatis Menggunakan Mikrokontroler Arduino UNO. Jurnal Teknologi dan Sistem Tertanam, 1(1), 17-22.

[10] Noor, A., Supriyanto, A., \& Rhomadhona, H. (2019). Aplikasi Pendeteksi Kualitas Air Menggunakan Turbidity Sensor Dan Arduino Berbasis Web Mobile. Jurnal CoreIT: Jurnal Hasil Penelitian Ilmu Komputer dan Teknologi Informasi, 5(1), 13-18.

[11] Nurazizah, E., Ramdhani, M., \& Rizal, A. (2017). Rancang Bangun Termometer Digital Berbasis Sensor DS18B20 Untuk Penyandang Tunanetra. eProceedings of Engineering, 4(3).

[12] Sari, K., \& Cucu Suhery, Y. A. (2015). Implementasi Sistem Pakan Ikan Menggunakan Buzzer Dan Aplikasi Antarmuka Berbasis Mikrokontroler. Coding Jurnal Komputer dan Aplikasi, 3(2).

[13] Wardhany, V. A. (2019, August). PEMBERI PAKAN OTOMATIS UDANG VANAMMEI 
MENGGUNAKAN METODE FUZZY LOGIC. In Prosiding Seminar Nasional Teknologi Elektro Terapan (Vol. 3, No. 1, pp. 17-23).

[14] Astria, J. and Fitrani, M., 2013. Kelangsungan Hidup dan Pertumbuhan Ikan Gabus (Channa Striata) pada Berbagai Modifikasi pH Media Air
Rawa yang diberi Substrat Tanah. Jurnal Akuakultur Rawa Indonesia, 1(1), pp.66-75.

[15] Listyanto, N. and Andriyanto, S., 2009. Ikan gabus (Channa striata) manfaat pengembangan dan alternatif teknik budidayanya. Media Akuakultur, 4(1), pp.18-25. 